\title{
RETRACTED ARTICLE: Health Effects and Safety of Magnetic Resonance Imaging
}

Kwan-Hoong Ng • Oliver Faust • Rajendra Acharya U

Received: 15 January 2010 /Accepted: 2 March 2010 / Published online: 30 March 2010

(C) Springer Science+Business Media, LLC 2012

This article has been retracted due to copyright violation.

This article has been retracted due to copyright violation.

K.-H. Ng $(\bowtie)$

Department of Biomedical Imaging, University of Malaya,

Kuala Lumpur, Malaysia

e-mail: aru@np.edu.sg

O. Faust $\cdot$ R. Acharya U

Department of Electronics and Computer Engineering,

Ngee Ann Polytechnic,

Clementi, Singapore 